\title{
Synthesis and Study of Thermo Physical Properties of Phthalic anhydride glycerol Resin (PAGR) from Soybean Oil
}

\author{
Shafqat Abbas ${ }^{1} \&$ Zaheer Ahmad $^{2}$ \\ ${ }^{1}$ Instittue of chemical engineering \& Technology University of the Punjab Lahore Pakistan, Pakistan \\ ${ }^{2}$ Minhaj University Lahore Pakistan, Pakistan \\ Correspondence: Shafqat Abbas, Instittue of chemical engineering \& Technology University of the Punjab Lahore \\ Pakistan, Pakistan. E-mail: engrabbas6@gmail.com
}

Received: November 27, 2019

Accepted: December 23, 2019

Online Published: December 31, 2019

doi:10.5539/jmsr.v9n1p42

URL: https://doi.org/10.5539/jmsr.v9n1p42

\begin{abstract}
Phthalic anhydride-glycerol Resin(PAGR) increase the flexibility of paint, resist to acid rain effect, increases the adhesiveness, brushing power, film hardness, layer flexibility, durability, gloss retention, resistance to abrasion also helps to decrease the overall drying time of paints. Phthalic anhydride-glycerol Resin is produced by reacting polyfunctional alcohol with the poly basic and monofunctional acid by Alcoholysis process. Moreover, Phthalic anhydride-glycerol Resin (PAGR) is a major raw material for coatings, varnishes and binders. Phthalic anhydride-glycerol Resin (PAGR) is used in paints coating compositions, adhesive, plastics, varnishes, printing ink, floor coverings. In the present research work, Phthalic anhydride-glycerol Resin is synthesized using soybean oil, pentaerythritol, phthalic anhydride and litharge $(\mathrm{PbO})$. It was further characterized by FTIR, DSC TGA and acid value.
\end{abstract}

Keywords: Alcoholysis method, phthalic anhydride glycerol Resin, soybean oil, Pentaerythritol and litharge

\section{Introduction}

Resins are complex oil modified polyesters that serves as the film forming agent in some paints and clear coating (Kanai, Mahato, \& Kumar, 2007). Resin and emulsion both are two types of polymer. Phthalic anhydride-glycerol Resin is the most important class of polymer. There are two types of resins that are used in paints, Alkyd Resin is used in solvent base paints and polyvinyl acetate resins (PVA) is used in water based paints. Alkyd resins are of two types, drying and nondrying. For the "drying" resins, triglycerides derived from poly unsaturated fatty acids (often derived from plant and vegetable oils, e.g. soybean oil). These drying alkyds resin are cured in air. Rate of drying and the depend on the quantity and type of drying oil used. Metal salts complex that catalyze cross linking of the unsaturated sites. Alkyd coatings are produced in two processes; fatty acid process and the Alcoholysis process. More economical alkyd resins are produced from the Alcoholysis (Ikhuoria et al., 2007; Jones, 2000).

Phthalic anhydride-glycerol Resin (PAGR) is used in coating compositions, adhesive, plastics, varnishes, printing ink, floor coverings and as a binder. It is estimated that $70 \%$ of the conventional binder is used in surface coating today. Phthalic anhydride-glycerol Resin (PAGR) is used in clear and pigmented, industrial and trade coating to protect as well as decorate a wide variety of substances. The industrial coatings or finishes generally are applied during the manufacturing process of their item. The industrial finishes include primers and top coating for refrigerators, furniture, and electrical equipment. In view of the development of these items and sectors, the positive growth is expected for paint industry (Bielman, 2000; Waters, 1955).

Airegumen I Aigbodion et al studied enhancing the quality of Phthalic anhydride-glycerol Resin using methyl esters of rubber seed oil in 2004 (Ikhuoria, Aigbodion, \& Okieimen, 2004). Edwin A. Murillo synthesized and characterized of hyper branched alkyd resins based on tall oil fatty acids. The primary goal of this study was to replace a percentage of the organic solvent used in the alkyd-based coatings in order to reduce the volatile organics needed for application viscosity (Murillo, Vallejo, \& Lopez, 2010).

Furthermore, the paint industry demand a future expansion in view of development in Automobile Industry, development in Corrosion Resistant Coatings, expansion in housing activity and other industry uses. Phthalic anhydride-glycerol Resin (PAGR) increase the flexibility, decrease over all drying time; minimize acid rain 
effect of the paint. The most important issues are Drying time, decreasing gloss and shining, acid rain effect, light effect on paints and mixing of ingredient. These problems can be resolve by using PAGR in paint as well as Phthalic anhydride-glycerol Resin increase increases the adhesiveness, brushing power, film hardness, flexibility, durability, gloss retention, resistance to abrasion of the paints (Kirk-Othmer, 2004; Sandler, Karo, Bonesteel, \& Pearce, 1998; Uschanov, Heiskanen, Mononen, Maunu, \& Koskimies, 2008).

\section{Materials and Methodology}

Alkali refined soybean oil was used for PAGR synthesis was acquired from Shan oil Ltd Pakistan 100\% pure, pentaerythritol, $\mathrm{PbO}$, methanol (95\%), potassium hydroxide solution, phenolphthalein, phthalic anhydride, Xylene (5\% of oil weight). Alkali refined Soybean oil, technical pentaerythritol, $\mathrm{PbO}$ charged to three neck flasks. By applying a slow inert gas flow of nitrogen at $0.02 \mathrm{ft}^{3} / \mathrm{min}$ and heated at $235^{\circ} \mathrm{C}$ temperature for two hours. Maintained $235^{\circ} \mathrm{C}$ temperature until one milliliter of the flask contents shows a clear solution with two milliliters anhydrous methanol. The acid value was determined by using titration method. A known amount of sample was dissolved in ethanol-toluene (1:1) solution and titrated with potassium hydroxide solution using phenolphthalein as an indicator. Total acid number (TAN) was calculated according to the following equation:

$$
\mathrm{TAN}=\mathrm{A} \times \mathrm{N} \times 56.1 / \mathrm{W}
$$

Where $\mathrm{A}$ is the consumption of $\mathrm{KOH}$ solution $(\mathrm{ml}), \mathrm{N}$ is the normality of the $\mathrm{KOH}$ solution and $\mathrm{W}$ is the weight of sample (gm). After the confirmation of esterification reaction, added phthalic anhydride and Resin formation contuing stirring and use about $5 \%$ of Xylene ( $5 \%$ of oil weight) as an azeotropic agent to facilitate removal of water of esterification. Maintain temperature at $245^{\circ} \mathrm{C}$ until the acid values of the system falls below $9 \mathrm{mg} \mathrm{KOH} /$ gm oil.

The Alcoholysis reaction is one of the two major reactions occurring during PAGR, the other being is esterification. The condition of reaction is critical factors in the Alcoholysis procedure. As might be expected, high temperatures facilitate the reaction but often are avoided because of possible development of highly colored products. Both alkaline and acidic reagent can be used to catalyzed the Alcoholysis but it has been determined that the acidic catalyst frequently contribute to dark colors in the reaction product. Some factors affecting the colors of an Alcoholysis mixture are contact with air and concentration of catalyst and temperature of the reaction. Alcoholysis is preferably carried out in the presence of an inert gas to prevent contact with oxygen and by using the least quantity of catalyst and lowest temperature necessary to accomplish the reaction in a reasonable period of time (Long, 1967). The prepared PAGR is characterizes by FTIR by IR Prestige 21 SHIMADZU Japan, DSC and TGA by Thermogravimetry analyzer model SDTQ600 TA instrument USA.

\section{Results \& Discussion}

\subsection{Synthesis of PAGR}

Rate of reaction decrease with the passage of time shown in Figure 1. Chemical resistance of the resin shown in Table 1, distilled water have no effect on the resin layer for $24 \mathrm{Hrs}$, if acidic solution is used, it is Blistering it. We have come to know that it is suitable for paints and resistant to acid rain and humidity in the air Esterification reaction was fast at the starting and slow after interval due to the consumotion of fatty acid in esterification during the formation of PAGR. when reaction was complete, it was observed that rate of reaction is fast at initial level but with the passage of time rate of reaction slow due to the consumotion of fatty acid.

Table 1. Acid of Pentaerythritol anhydride Glycerol Resin

\begin{tabular}{ccc}
\hline Properties & Observed & Range (ASTM method) \\
\hline Acid value & 7.2 & less than 10 \\
\hline
\end{tabular}

\subsection{Rate of Reaction}

In esterification reaction, it was observed that the longer the reaction time, viscous the resin. In this stage adequate agitation is required for the complete mixing of pentaerythritol with phthalic anhydride so $\mathrm{N}_{2}$ rate was increased to remove the liberated product and to increase the heat and mass transfer. The reaction should not further proceed if the Acid Value of the resin had dropped 7.2 because the reaction was closed to gel point (khuoria, Aigbodion, \& Okieimen, 2004). As shown in Figure 2, the acid value of the contents decreases as the quantity of the fatty acid of oil used, consumed in the esterification reaction during the formation of Phthalic 
anhydride-glycerol Resin take place. The reaction is fast at the starting, with the passage of time the amount of fatty acid decrease that's why rate of reaction decrease

Table 2. Rate of reaction $(1 \mathrm{ml}$ sample $+2 \mathrm{ml}$ methanol)

\begin{tabular}{lll}
\hline Time (Minutes) & Temperature $\left({ }^{\circ} \mathrm{C}\right)$ & Physical state \\
\hline 0 & 230 & Immiscible \\
30 & 210 & Immiscible \\
60 & 220 & Immiscible \\
90 & 228 & Partially miscible \\
120 & 230 & Nearly complete \\
150 & 235 & soluble \\
\hline
\end{tabular}

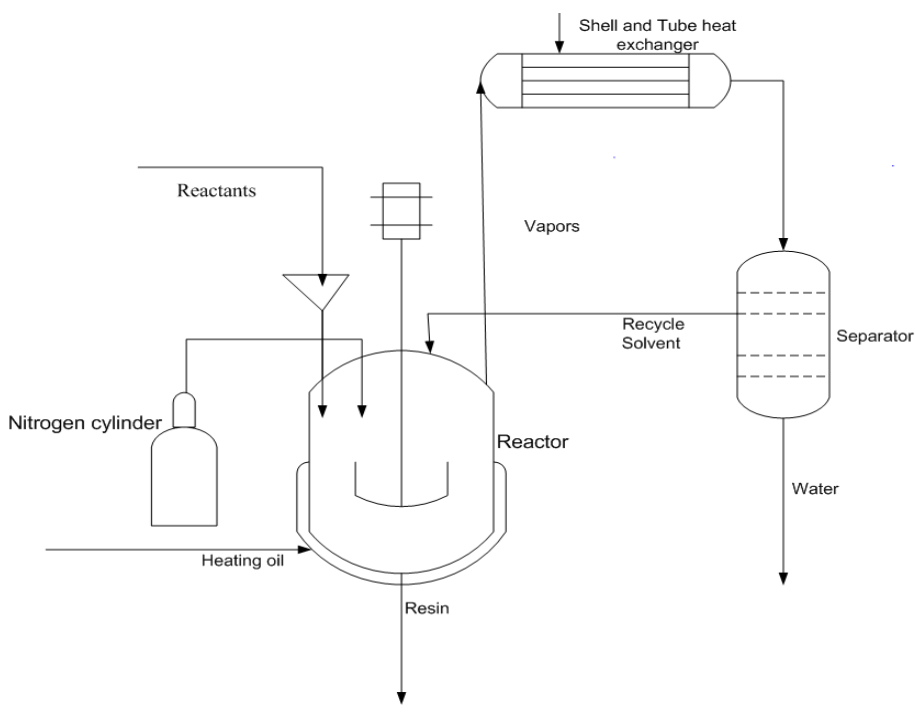

Figure 1. Process flow diagram of pentaerythritol phthalic anhydride resin

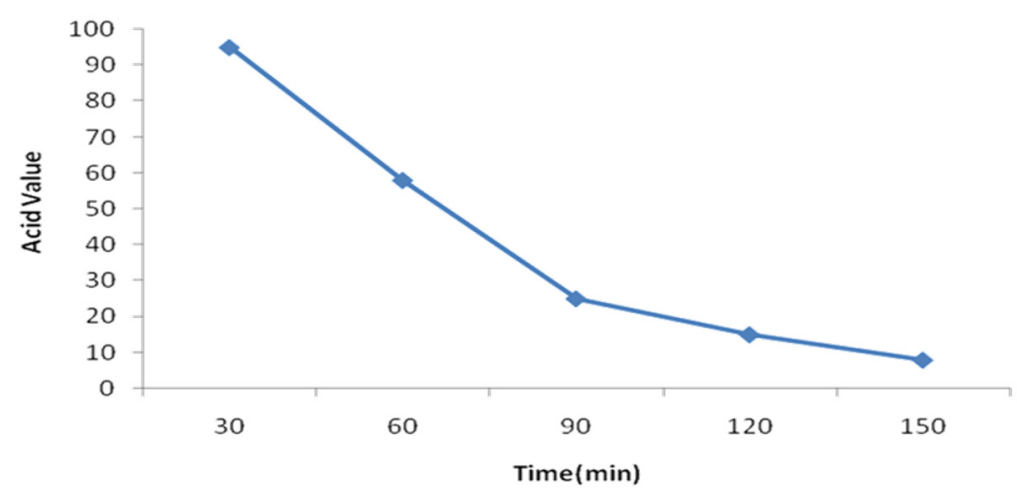

Figure 2. Rate of reaction

\subsection{Characteristics of PAGR}

There is no common standard to compare Phthalic anhydride-glycerol Resin. Each alkyd resin has its own properties. The Resin that has acid value less than 15 is suitable for the application of paints (Jones, 2000; Waters, 1955) and Phthalic anhydride-glycerol Resin acid value, $7.2 \mathrm{mgKOH} / \mathrm{gm}$ oil. The one important variable during the study of alkyd resin formulation of the resin is the layer formation which was observed physically by applying on the surface (Mehlenbancher, 1950). 
Table 3. Acid value test ( $\mathrm{ml} \mathrm{KOH} / \mathrm{mg}$ oil)

\begin{tabular}{lll}
\hline Time (Minutes) & Temperature $\left({ }^{\circ} \mathrm{C}\right)$ & Acid value \\
\hline 0 & 240 & No result \\
30 & 235 & 95 \\
60 & 238 & 54 \\
90 & 240 & 20 \\
120 & 245 & 11 \\
150 & 245 & 7.2 \\
\hline
\end{tabular}

\subsection{Chemical resistance of Phthalic anhydride-glycerol Resin film}

The resistance of Phthalic anhydride-glycerol Resin determined in two media, distilled water and $\mathrm{H}_{2} \mathrm{SO}_{4}(3 \mathrm{PH})$ solution. There is no effect on Phthalic anhydride-glycerol Resin film after immersions in water for 24 hours. When Phthalic anhydride-glycerol Resin film was immersed in $\mathrm{H}_{2} \mathrm{SO}_{4}(\mathrm{PH} 3)$ the film was got whitening after 8 hours and blistering after 20 hours and after 36 hours it was removed

Table 4. Chemical resistance Pentaerythritol phthalic anhydride of alkyd resin

\begin{tabular}{lll}
\hline Media & Immersion time (hours) & Appearance of film \\
\hline Distilled water & 24 & No effect \\
$3 \mathrm{PH}$ & 20 & Blistring \\
Solution $\left(\mathrm{H}_{2} \mathrm{SO}_{4}\right)$ & 36 & Removal \\
\hline
\end{tabular}

\subsection{FTIR Adsorption of Phthalic anhydride-glycerol Resin}

The FTIR spectrum of prepared PPR exhibits a characteristics of aromatic ring ester band at $1730.15 \mathrm{c} / \mathrm{m}$. the present of $\mathrm{O}=\mathrm{C}-\mathrm{O}-\mathrm{C}-$ also exhibit the characteristics ester at $1730.15 \mathrm{c} / \mathrm{m}$ The appearance of $\mathrm{CH} 2,-\mathrm{CH}-\mathrm{confirm}$ the present of methyl group at $1460.11 \mathrm{c} / \mathrm{m} ., 2854.65 \mathrm{c} / \mathrm{m}$ the adsorption band at $2924.09 \mathrm{c} / \mathrm{m}$ is the characteristics of alkenes carbon =C-H (Aydin, Akçay, Özkan, Güner, \& Erciyes, 2004; Sandler et al., 1998; Mehlenbancher, $1950)$ and $-\mathrm{OH}$ at $3396.64 \mathrm{c} / \mathrm{m}, 1068 \mathrm{c} / \mathrm{m}$. the presence of hydroxyl group is responsible of stretching power of the resin, if the function group $-\mathrm{OH}$ increase then its stretching power will also be increase $\mathrm{C}=\mathrm{O}$ is responsible stretching, in the fatty acid to $1730 \mathrm{c} / \mathrm{m}$ in the resin (characteristic of ester) which indicate the poly esterification reaction evidenced for the transformation of the carboxylic acid in ester (Murillo et al., 2010). In alkyl coating, drying occurs due to the oxidation of the fatty acid, and decomposition of the hydroperoxides and cross linking between the fatty acid chains. Oxidation begin with the hydrogen abstraction in the methylen group activated by the two bonds present in linolenic or linolenic acid of the fatty acid in oil by complex process of radical polymerization. Cross-linking occurs by radical addition with conjugated double bonds or radical recombination with formation of an alkyl (carbon-carbon) (Uschanov et al., 2008).

Table 5. FTIR Absorption of PAGR

\begin{tabular}{llll}
\hline Band number & Experimental frequency $(\mathrm{c} / \mathrm{m})$ & Literature frequency $(\mathrm{c} / \mathrm{m})$ & Remarks \\
\hline 1. & 2924.09 & near 3030 & $=\mathrm{C}-\mathrm{H}$ \\
2. & 3396.64 & $3200-3570$ & $\mathrm{O}-\mathrm{H}$ \\
& 1068 & Near 1100 & $\mathrm{O}-\mathrm{H}$ \\
3. & 2854.65 & $2850-2926$ & $\mathrm{C}-\mathrm{H}$ \\
4 & 1460.11 & $1440-1485$ & $\mathrm{CH}_{2}$ \\
5 & 1730.15 & $1717-1730$ & $\mathrm{COO}$ \\
\hline
\end{tabular}




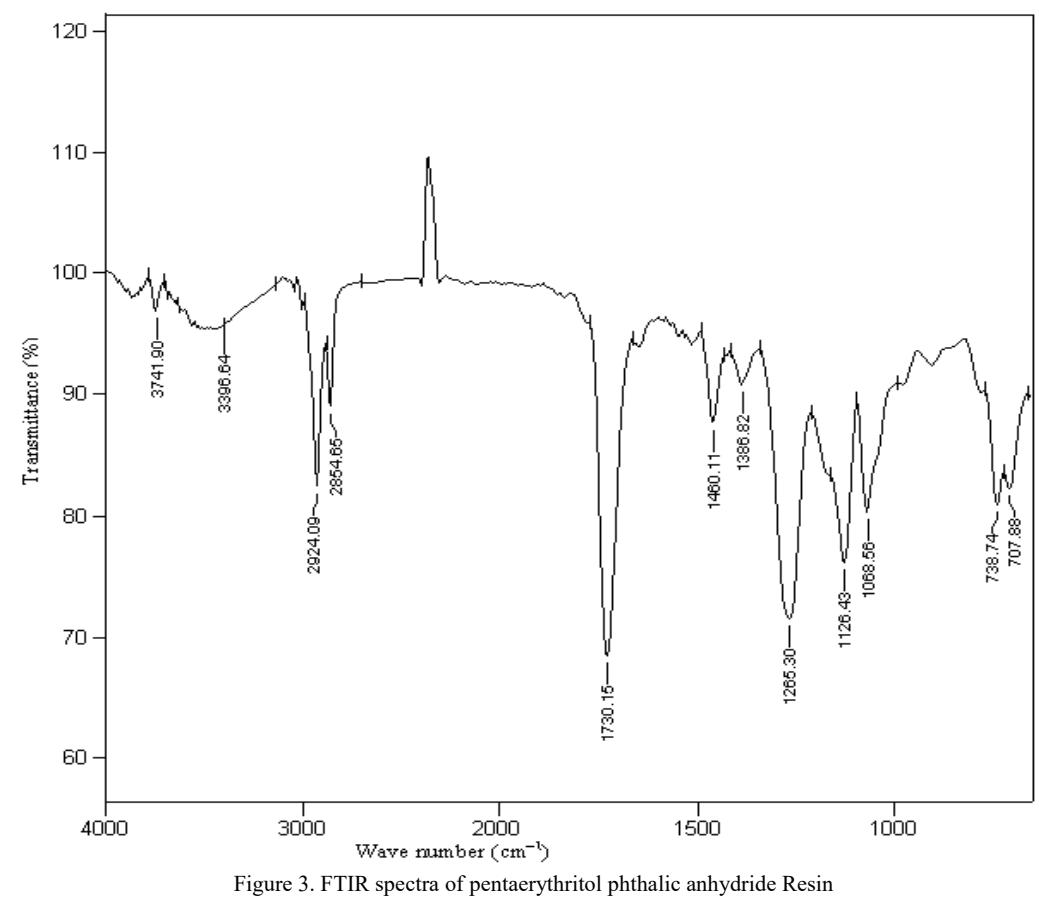

\section{Thermal Analysis}

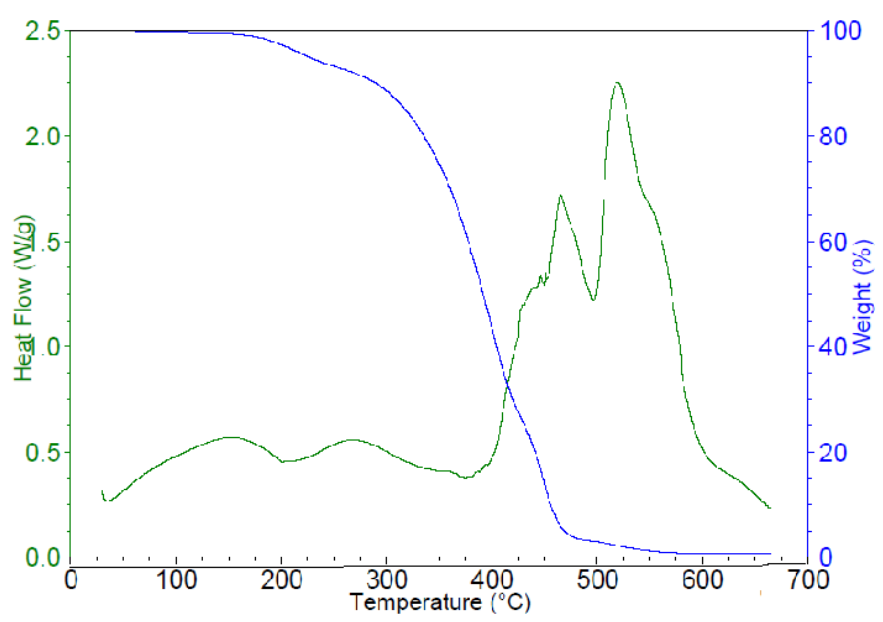

Figure 4. Comparison heat flow and temperature with weight loss

The thermal degradation temperature of PAGR has initials and final thermal degradation temperature is $200^{\circ} \mathrm{C}$, $670^{\circ} \mathrm{C}$ respectively. There is comparison by increasing heat flow rate temperature will also increase and weight loss also increases in Figure 4. Rebecca Ploeger developed an alkyd resin loss $100 \%$ weight at $470^{\circ} \mathrm{C}$ (Ploeger, Scalarone, \& Chiantore, 2009). Güçlü and Orbay (2009) synthesized an alkyd resin loss $100 \%$ weight at $500^{\circ} \mathrm{C}$. From this development PAGR is more stable than the previous developed resin. PAGR is more stable due the presence of large number of $-\mathrm{OH}$ group which increase the stretching power of the resin.

\section{Conclusion}

Lead oxide decrease the reaction time as Lead oxide the give the complete Alcoholysis to precede esterification reaction after reaction time for two hours. Alkali refined soybean oil was used in the preparation of Phthalic anhydride-glycerol Resin. The acid value of Phthalic anhydride-glycerol Resin is $7.2 \mathrm{mgKOH} / \mathrm{gm}$ oil by using pentaerythritol, phthalic anhydride and with the help of $\mathrm{PbO}$ as a catalyst. The physico - chemical properties by DSC, TGA and FTIR study of a PAGR showed that its increase the flexibility; decrease overall drying time and high chemical resistance. It enhances the quality of the paint by layer formation. 


\section{References}

Aydin, S., Akçay, H., Özkan, E., Güner, F. S., \& Erciyes, A. T. (2004). The effects of anhydride type and amount on viscosity and film properties of alkyd resin. Progress in Organic Coatings, 51(4), 273-279.

Bielman, J. H. (2000). Additives for coatings. Weinheim: Wiley-VCH.

Güçlü, G., \& Orbay, M. (2009). Alkyd resins synthesized from postconsumer PET bottles. Progress in Organic Coatings, 65(3), 362-365.

Ikhuoria, E. U., Aigbodion, A. I., \& Okieimen, F. E. (2004). Enhancing the quality of alkyd resins using methyl esters of rubber seed oil. Tropical Journal of Pharmaceutical Research, 3(1), 311-317.

Ikhuoria, E. U., Maliki, M., Okieimen, F. E., Aigbodion, A. I., Obaze, E. O., \& Bakare, I. O. (2007). Synthesis and characterisation of chlorinated rubber seed oil alkyd resins. Progress in organic coatings, 59(2), 134-137.

Jones, F. N. (2000). Alkyd resins. Ullmann's Encyclopedia of Industrial Chemistry. Weinheim: Wiley-VCH,.

Kanai, T., Mahato, T. K., \& Kumar, D. (2007). Synthesis and characterization of novel silicone acrylate-soya alkyd resin as binder for long life exterior coatings. Progress in Organic Coatings, 58(4), 259-264.

Kirk-Othmer. (2004). Kirk-Othmer Encyclopedia of Chemical Technology (Volume 2, 5th ed.).

Long, J. S. (1967). Filming forming composition (vol. 1). New York.

Mehlenbancher, V. C. (1950). Official and testing methods for the American oil chemists society Chicago: 35 east Wacker Drive 1950.

Murillo, E. A., Vallejo, P. P., \& Lopez, B. L. (2010). Synthesis and characterization of hyperbranched alkyd resins based on tall oil fatty acids. Progress in Organic Coatings, 69(3), 235-240.

Ploeger, R., Scalarone, D., \& Chiantore, O. (2009). Thermal analytical study of the oxidative stability of artists' alkyd paints. Polymer Degradation and Stability, 94(11), 2036-2041.

Sandler, S. R., Karo, W., Bonesteel, J., \& Pearce, E. M. (1998). Polymer synthesis and characterization: a laboratory manual. Elsevier.

Uschanov, P., Heiskanen, N., Mononen, P., Maunu, S. L., \& Koskimies, S. (2008). Synthesis and characterization of tall oil fatty acids-based alkyd resins and alkyd-acrylate copolymers. Progress in Organic Coatings, 63(1), 92-99.

Waters, R. T. (1955). Resins-Synthetic, Alkyd Resins, Section 2. London: Wyman and Sons, Ltd..

\section{Copyrights}

Copyright for this article is retained by the author(s), with first publication rights granted to the journal.

This is an open-access article distributed under the terms and conditions of the Creative Commons Attribution license (http://creativecommons.org/licenses/by/4.0/). 